\title{
Partial liquid ventilation: effects of liquid volume and ventilatory settings on perfluorocarbon evaporation
}

\author{
S.A. Loer, D. Kindgen-Milles, J. Tarnow
}

Partial liquid ventilation: effects of liquid volume and ventilatory settings on perfluorocarbon evaporation. S.A. Loer, D. Kindgen-Milles, J. Tarnow. (C)ERS Journals Ltd 2002.

ABSTRACT: During partial liquid ventilation perfluorocarbons are eliminated mainly by evaporation via the airways. The effects of intrapulmonary perfluorocarbon volume, respiratory rate, tidal volume, as well as the level of end-expiratory pressure on perfluorocarbon elimination from isolated lungs, were studied.

Nonperfused rabbit lungs underwent partial liquid ventilation $\left(2-15 \mathrm{~mL} \cdot \mathrm{kg}^{-1}\right.$ perfluorocarbon) with variable levels of end-expiratory pressure $\left(0-10 \mathrm{cmH}_{2} \mathrm{O}\right)$, respiratory rates $\left(15-60\right.$ breaths $\left.\cdot \mathrm{min}^{-1}\right)$ and tidal volumes $\left(3.3-10.0 \mathrm{~mL} \cdot \mathrm{kg}^{-1}\right)$. Evaporative loss of perfluorocarbon was determined gravimetrically as rate of change in lung weight.

At constant respiratory settings, intrapulmonary liquid volume determined evaporative loss in a nonlinear fashion. Mean evaporation at a liquid volume of $5 \mathrm{~mL} \cdot \mathrm{kg}^{-1}$ was $13 \%$ lower compared to evaporation at a liquid volume of $15 \mathrm{~mL} \cdot \mathrm{kg}^{-1}$. Any increase in end-expiratory pressure reduced perfluorocarbon evaporation, e.g. by $\sim 50 \%$ when end-expiratory pressure was increased from 0 to $10 \mathrm{cmH}_{2} \mathrm{O}$. At constant endexpiratory pressure and perfluorocarbon filling evaporation increased in a linear fashion with increasing respiratory rate and tidal volume.

In summary, the experiments suggested that evaporative loss of perfluorocarbons during partial liquid ventilation of isolated lungs is increased with increasing intrapulmonary liquid volume, respiratory rate and tidal volume and is reduced in a level-dependent fashion by the application of positive end-expiratory pressure.

Eur Respir J 2002; 20: 1499-1504.
Dept of Anaesthesiology, HeinrichHeine-University, Düsseldorf, Germany.

Correspondence: S.A. Loer

Klinik für Anaesthesiologie

Universitätsklinikum Düsseldorf

Moorenstr. 5, 40225

Düsseldorf

Germany

Fax: 492118119639

E-mail: loer@med.uni-duesseldorf.de

Keywords: Liquid ventilation

lung

perfluorocarbons

positive pressure ventilation

rabbits

Received: November 282001

Accepted after revision: June 182002
During partial liquid ventilation perfluorocarbons are instilled into the airways from where they are subsequently eliminated by evaporation via the bronchial system. This process is influenced by various factors, like the physicochemical properties of the liquids (especially vapour pressure), the dose instilled into the airways, intrapulmonary perfluorocarbon distribution and respiratory settings [1-6]. Only small amounts cross the alveolo-capillary membranes into the vascular space and are stored in intra- and extrathoracic lymph nodes as well as in other organs indicating systemic distribution [7-9].

A major variable which appears to influence perfluorocarbon elimination is the amount of liquid within the lungs. It has been observed before that perfluorocarbon evaporation is not a constant process, but decreases over time [3]. Elimination also depends on the ventilatory settings, especially respiratory rate and tidal volume. In addition, the level of end-expiratory pressure may affect elimination since superimposing a positive end-expiratory pressure (PEEP) during partial liquid ventilation may increase functional residual capacity and alveolar ventilation [10-16]. Such effects are likely to influence intrapulmonary perfluorocarbon distribution as well as the air/liquid interface from which perfluorocarbons evaporate in the expired gas during partial liquid ventilation.

It is difficult to control and vary these variables independently from each other during in vivo measurements. Therefore, experiments in isolated lungs, which allowed independent variations of these factors, were performed and the impact of each variable was analysed systematically. The experimental approach allowed for the measurement of intrapulmonary perfluorocarbon volume continuously by gravimetry. The aim of the experiments was to study the effects of intrapulmonary liquid volume on perfluorocarbon evaporation at constant respiratory settings as well as the effects of ventilatory settings (respiratory rate, tidal volume and end-expiratory pressure) at controlled intrapulmonary liquid volume.

\section{Materials and methods}

\section{Isolated lung preparation and measurements}

With approval of the Institutional Review Board for the care and use of animal subjects and in accordance with the guidelines of the Helsinki convention, New Zealand white rabbits of either sex 
(body weight $2.4-3.4 \mathrm{~kg}$ ) were anaesthetised with $30 \mathrm{mg} \cdot \mathrm{kg}^{-1}$ pentobarbital sodium i.v. Following midline sternotomy, the trachea, heart and lungs were removed en bloc and suspended from a force transducer (initial weight 30-35 g). This upright position was kept constant throughout the experiments. The isolated lungs were inflated for a short time period with positive pressures $\left(\leqslant 20 \mathrm{cmH}_{2} \mathrm{O}\right)$ until any visible atelectases had resolved. Subsequently, the lungs were allowed to deflate again (initial gas volume) and were then ventilated with $5 \%$ carbon dioxide $\left(\mathrm{CO}_{2}\right)$ in air with a tidal volume of $10 \mathrm{~mL} \cdot \mathrm{kg}^{-1}$, a respiratory rate of 30 breaths $\cdot \mathrm{min}^{-1}$ and an inspiration/expiration ratio of 1:1 (Harvard Respirator, model 683; Harvard Apparatus, South Natick, MA, USA). Thereafter, the lungs were completely covered with a thin plastic foil (Plus, Mühlheim, Germany), which was impermeable to perfluorocarbons (liquid and vapour) and which prevented drying of the isolated lungs via the pleura. Premixed gas $\left(5 \% \mathrm{CO}_{2}\right.$ in air was supplied by Messer Griesheim GmbH (Duisburg, Germany)).

A PEEP was adjusted to the appropriate level by means of a water seal in the expiratory limb of the breathing circuit.

Changes in lung weight were measured continuously with a force transducer (model FT 03; Grass Instruments, Quincy, MA, USA) which was calibrated before and after each experiment and which had the following specifications: stability $\pm 1 \%$, resolution as high as 25,000:1 and drift $<50 \mathrm{mg} \cdot \mathrm{h}^{-1}$. Airway pressure was measured with an electromanometer referenced to atmospheric pressure (P23 ID; Statham, Gould, Oxnard, CA, USA).

\section{Partial liquid ventilation}

Perfluorocarbon was instilled via a side port of the tracheal tube into the airways of the lungs without interrupting mechanical ventilation. The compound used (PF-5080; 3M, Neuss, Germany) had the following physicochemical characteristics: chemical structure $\mathrm{C}_{8} \mathrm{~F}_{18}$, specific gravity $1.77 \mathrm{~g} \cdot \mathrm{mL}^{-1}$, surface tension 15 dynes $\cdot \mathrm{cm}^{-1}$, vapour pressure $5.9 \mathrm{kPa}$ (44 Torr) at $25^{\circ} \mathrm{C}$ and dynamic viscosity $1.4 \mathrm{mPa} \cdot \mathrm{s}^{-1}$.

\section{Experimental protocol}

Only lungs without any signs of air or liquid leaks (loss of airway pressure when ventilation was stopped in inspiration or evidence of liquid accumulation in the plastic foil covering the lung) were included in the experimental protocol.

Control lungs were either gas ventilated without instillation of perfluorocarbon $(n=6)$ or received $10 \mathrm{~mL}$ perfluorocarbon $\cdot \mathrm{kg}$ body weight ${ }^{-1}$ without subsequent ventilation $(n=6)$, to exclude the influence of dry gas ventilation or ventilation-independent perfluorocarbon loss (e.g. via the pleura) on weight measurements. Water weight lost from nonperfused gas-ventilated lungs in this preparation was $<0.1 \mathrm{~g} \cdot \mathrm{h}^{-1}$. Six further control lungs were filled with $10 \mathrm{~mL}$ perfluorocarbon $\cdot \mathrm{kg}$ body weight ${ }^{-1}$ and ventilated until lung weight returned to baseline value (respiratory rate 30 breaths $\cdot \mathrm{min}^{-1}$, tidal volume $10 \mathrm{~mL} \cdot \mathrm{kg}^{-1}$ and PEEP $5 \mathrm{cmH}_{2} \mathrm{O}$ ). Experiments were performed at a constant room temperature $\left(20^{\circ} \mathrm{C}\right)$ without moisturising of respiratory gases, which might have influenced perfluorocarbon elimination as well as weight measurements due to intrapulmonary water condensation.

The effects of end-expiratory pressure and intrapulmonary liquid volume on perfluorocarbon evaporation were studied in six lungs. Variable levels of end-expiratory pressure $\left(0,2.5,5\right.$ and $\left.10 \mathrm{cmH}_{2} \mathrm{O}\right)$ were applied in a random order (drawing numbers) and maintained for $15 \mathrm{~min}$. Before the level of end-expiratory pressure was changed the evaporated perfluorocarbon volume was replaced by appropriate supplemental instillation of perfluorocarbon to keep intrapulmonary liquid volume constant. Thereafter, intrapulmonary perfluorocarbon volume was increased in a stepwise manner to establish intrapulmonary liquid volumes of $1,2,5,10$ and $15 \mathrm{~mL} \cdot \mathrm{kg}^{-1}$ perfluorocarbon. The variation of end-expiratory pressure was repeated for all volumes. During these experiments, the lungs were ventilated with a constant tidal volume of $10 \mathrm{~mL} \cdot \mathrm{kg}^{-1}$ body weight and a respiratory rate of 30 breaths $\cdot \mathrm{min}^{-1}$. At the end of the experiments (after $5 \mathrm{~h}$ and when the lungs were filled with $15 \mathrm{~mL} \cdot \mathrm{kg}^{-1}$ perfluorocarbon) they were ventilated overnight to ensure that weight returned to or below baseline. Perfluorocarbon evaporation at a liquid volume of 10 and $5 \mathrm{~mL} \cdot \mathrm{kg}^{-1}$ perfluorocarbon was compared with the evaporation at the corresponding liquid volumes ( 5 and $10 \mathrm{~mL} \cdot \mathrm{kg}^{-1}$ ) during the first part of the experiments to check the results for reproducibility and exclude relevant time-related effects.

In additional lungs $(n=6)$, the effects of respiratory rate and tidal volume at a constant intrapulmonary liquid volume of $10 \mathrm{~mL} \cdot \mathrm{kg}^{-1}$ perfluorocarbon and a PEEP of $5 \mathrm{cmH}_{2} \mathrm{O}$ were studied. For this purpose, respiratory rate $\left(15,30,45\right.$ and 60 breaths $\left.\cdot \mathrm{min}^{-1}\right)$ and tidal volume $\left(3.3,5.0,6.6\right.$ and $\left.10 \mathrm{~mL} \cdot \mathrm{kg}^{-1}\right)$ were varied in a random fashion. Each combination was maintained for $15 \mathrm{~min}$ (total time of experiments: $4 \mathrm{~h}$ ) and the lost perfluorocarbon volume was replaced by adequate bronchial instillation before the next combination was started.

\section{Statistical analysis}

Data are presented as mean \pm SD. Perfluorocarbon elimination was determined as loss of lung weight per time unit and presented as $\mathrm{mL} \cdot \mathrm{h}^{-1} \cdot \mathrm{kg}^{-1}$ body weight. For this purpose the slope of the weight/time relationship at the end of the 15-min period, before respiratory variables or intrapulmonary liquid volume were changed, was calculated. The following a priori null hypotheses were tested: 1) PEEP has no effect on evaporation at constant intrapulmonary liquid volume when compared to zero end-expiratory pressure; 2) a decrease in intrapulmonary liquid volume has no effect on evaporation at constant respiratory settings when compared to a volume of $15 \mathrm{~mL} \cdot \mathrm{kg}^{-1}$ 
perfluorocarbon; and 3) respiratory rate and tidal volume have no influence on evaporation at constant intrapulmonary liquid volume $\left(10 \mathrm{~mL} \cdot \mathrm{kg}^{-1}\right.$ perfluorocarbon) and PEEP $\left(5 \mathrm{cmH}_{2} \mathrm{O}\right)$.

Differences in mean values of variables were analysed by Friedman's test. Wilcoxon's signed-rank test was used to test differences if the null hypothesis was rejected by Friedman's test. A two-tailed $\alpha$-adjusted $p<0.05$ was considered statistically significant. The relationship between respiratory rate and evaporation for different tidal volumes was analysed by calculating the coefficients of the linear regression lines.

\section{Results}

With intratracheal perfluorocarbon instillation, lung weight increased markedly and returned to baseline value in a nonlinear fashion after several hours of ventilation, as shown in figure 1. In contrast, weight loss of perfluorocarbon-filled lungs that were not ventilated was $<0.5 \mathrm{~g}$ during an observation period of $4 \mathrm{~h}$, indicating that only negligible amounts of perfluorocarbon were lost independent of ventilation. Weight loss of gas-ventilated control lungs was also negligible compared to the weight loss of perfluorocarbon-ventilated lungs $(<0.4 \mathrm{~g}$ in $4 \mathrm{~h})$ so that the observed changes in weight predominantly

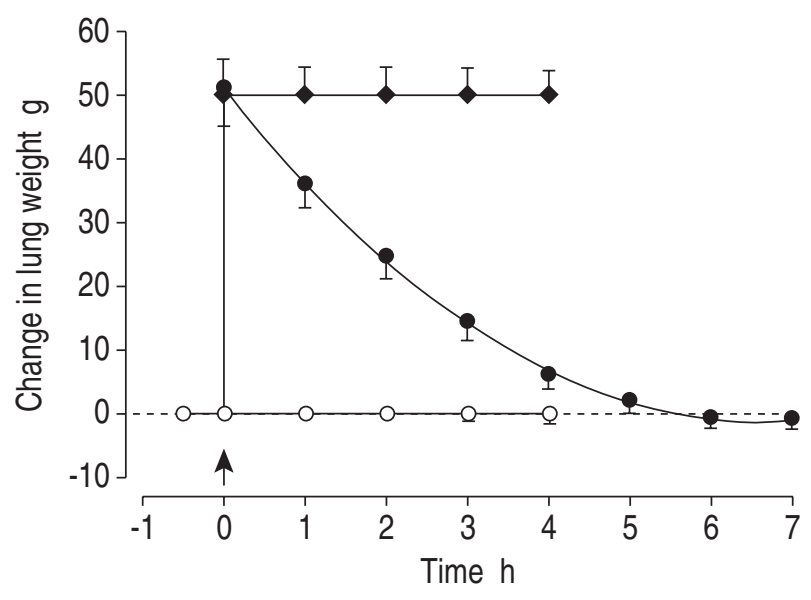

Fig. 1.-Changes in lung weight over time. Data are presented as mean \pm SD. Control lungs were either gas ventilated $(\bigcirc)$ (tidal volume $(V \mathrm{~T})=10 \mathrm{~mL} \cdot \mathrm{kg}^{-1}$, frequency $=30 \mathrm{breaths} \cdot \mathrm{min}^{-1}$, positive end-expiratory pressure $\left.(\mathrm{PEEP})=5 \mathrm{cmH}_{2} \mathrm{O}\right)$ or received $10 \mathrm{~mL} \cdot \mathrm{kg}^{-1}$ perfluorocarbon without subsequent ventilation $(\bullet)$. In both groups mean changes in lung weight during an observation period of $4 \mathrm{~h}$ was negligible suggesting that lung weight was not influenced in a relevant fashion by gas-ventilation or by ventilation-independent perfluorocarbon loss. During partial liquid ventilation (O) the lungs received $10 \mathrm{~mL} \cdot \mathrm{kg}^{-1}$ perfluorocarbon and were ventilated subsequently with $5 \%$ carbon dioxide in air $\left(V \mathrm{~T}=10 \mathrm{~mL} \cdot \mathrm{kg}^{-1}\right.$, frequency $=30$ breaths $\left.\cdot \mathrm{min}^{-1}, \mathrm{PEEP}=5 \mathrm{cmH}_{2} \mathrm{O}\right)$. Lung weight decreased in a nonlinear fashion and returned to or below baseline weight after several hours. With the applied respiratory settings and intrapulmonary liquid volume $\sim 50 \%$ of the instilled perfluorocarbon was evaporated after $2 \mathrm{~h}$ and $>90 \%$ after $4 \mathrm{~h}$. The arrow shows the instillation of $10 \mathrm{~mL} \cdot \mathrm{kg}^{-1}$ of perfluorocarbon.

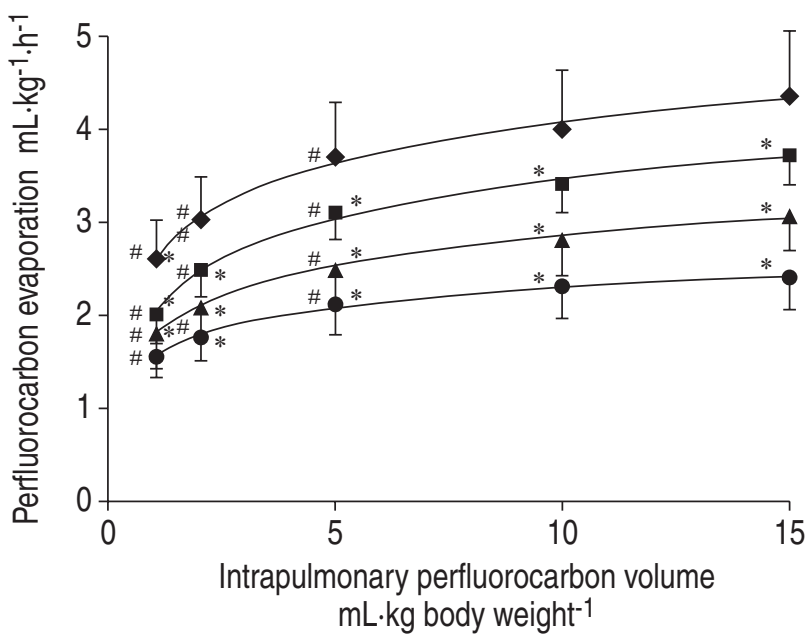

Fig. 2.-Effects of intrapulmonary perfluorocarbon volume on evaporative loss for different levels of end-expiratory pressure. Data from six isolated nonperfused rabbit lungs. Data are presented as mean $\pm S D$. Any increase in end-expiratory pressure significantly decreased perfluorocarbon elimination $(*: \mathrm{p}<0.05$ significant difference when compared to an end-expiratory pressure of $0 \mathrm{cmH}_{2} \mathrm{O}$ ). At the same time, evaporative loss decreased with decreasing intrapulmonary liquid volume (\#: $p<0.05$ significant difference when compared to an intrapulmonary liquid volume of $15 \mathrm{~mL} \cdot \mathrm{kg}^{-1}$ body weight). This effect was more pronounced with small volumes. The following end-expiratory pressures are represented $\left(\mathrm{cmH}_{2} \mathrm{O}\right) . \diamond: 0 ; \mathbf{\square}: 2.5 ; \boldsymbol{\Delta}: 5.0 ; \mathbf{O}: 10$.

reflected evaporative loss of perfluorocarbon via the airways of the lungs.

At constant respiratory settings, intrapulmonary liquid volume affected evaporation in a nonlinear fashion (fig. 2). Evaporation was 13\% lower at an intrapulmonary volume of $5 \mathrm{~mL} \cdot \mathrm{kg}^{-1}(3.7 \pm 0.59 \mathrm{~mL}$. $\left.\mathrm{kg}^{-1} \cdot \mathrm{h}^{-1}\right)$ when compared to an intrapulmonary liquid volume of $15 \mathrm{~mL} \cdot \mathrm{kg}^{-1}$ and $28 \%$ lower at a volume of $2 \mathrm{~mL} \cdot \mathrm{kg}^{-1}\left(3.0 \pm 0.41 \mathrm{~mL} \cdot \mathrm{kg}^{-1} \cdot \mathrm{h}^{-1}\right)$ at an end-expiratory pressure of $0 \mathrm{cmH}_{2} \mathrm{O}$. At the end of these experiments (when the lungs were filled with $15 \mathrm{~mL} \cdot \mathrm{kg}^{-1}$ perfluorocarbon) the lungs were ventilated overnight. Evaporation at liquid volumes of 10 and $5 \mathrm{~mL}$ perfluorocabon $\cdot \mathrm{kg}^{-1}$ differed $<5 \%$ from the initial determinations.

The effects of intrapulmonary liquid volume on perfluorocarbon evaporation during ventilation with different levels of end-expiratory pressure are also shown in figure 2. Any increase in end-expiratory pressure significantly decreased evaporation at constant intra-pulmonary liquid volumes, e.g. when the level was increased from zero to $10 \mathrm{cmH}_{2} \mathrm{O}$ at an intrapulmonary liquid volume of $15 \mathrm{~mL} \cdot \mathrm{kg}^{-1}$, mean perfluorocarbon evaporation decreased by $49 \%$ from $4.3 \pm 0.68$ to $2.4 \pm 0.31 \mathrm{~mL} \cdot \mathrm{kg}^{-1} \cdot \mathrm{h}^{-1}$.

The effects of respiratory rate on evaporative loss are presented in figure 3. At constant intrapulmonary liquid volume $\left(10 \mathrm{~mL} \cdot \mathrm{kg}^{-1}\right)$ and PEEP $\left(5 \mathrm{cmH}_{2} \mathrm{O}\right)$ evaporation increased in a linear fashion when respiratory rate was increased from 15 to 60 breaths $\cdot \mathrm{min}^{-1}$ $\left(\mathrm{r}^{2} 0.86-0.96\right)$. Similarly, any increase in tidal volume increased evaporative loss significantly at any given respiratory rate. 


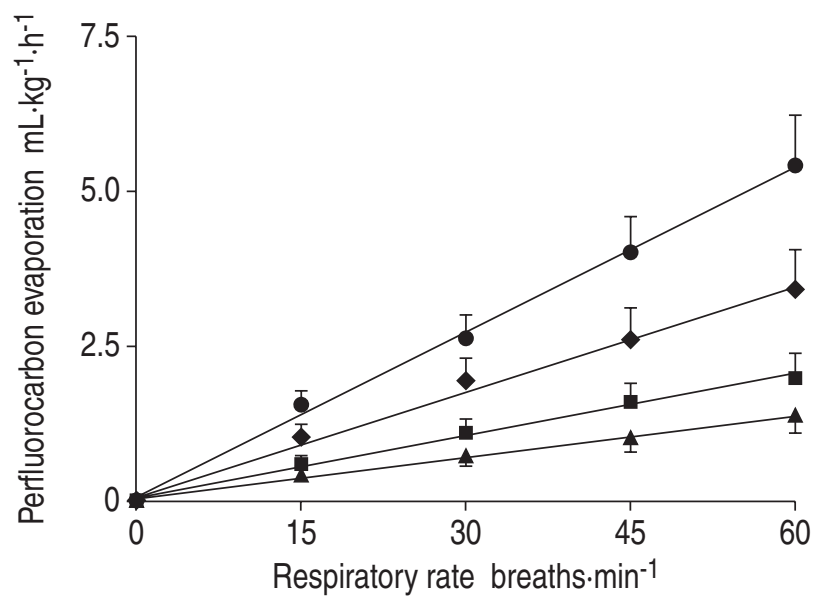

Fig. 3.-Effects of respiratory rate and tidal volume on evaporative loss at constant intrapulmonary perfluorocarbon volume $\left(10 \mathrm{~mL} \cdot \mathrm{kg}^{-1}\right)$ and positive end-expiratory pressure $\left(5 \mathrm{cmH}_{2} \mathrm{O}\right)$. Data from six isolated nonperfused rabbit lungs. Data are presented as mean $\pm S D$. With increasing respiratory rate and tidal volume evaporative perfluorocarbon loss increased in a linear fashion $\left(\mathrm{r}^{2}\right.$ coefficients of linear regression lines). The following tidal volumes are represented $\left(\mathrm{mL} \cdot \mathrm{kg}^{-1}\right)$. $0: 10\left(\mathrm{r}^{2}=0.89\right) ; \diamond: 6.6$ $\left(r^{2}=0.95\right) ; \boldsymbol{\square}: 5.0\left(r^{2}=0.96\right) ; \boldsymbol{\Delta}: 3.3\left(r^{2}=0.86\right)$.

\section{Discussion}

In this study the effects of intrapulmonary liquid volume, respiratory rate, tidal volume and endexpiratory pressure on perfluorocarbon evaporation during partial liquid ventilation of isolated lungs were investigated. In nonperfused rabbit lungs, it was observed that evaporation increased in a nonlinear fashion with increasing volumes of perfluorocarbon and with increasing respiratory rate and tidal volume, and was reduced with increasing levels of PEEP.

\section{Critique of methods}

The results were obtained from isolated lungs, which allowed for the effects of respiratory settings and intrapulmonary perfluorocarbon volumes on evaporation to be studied systematically, under controlled conditions and independent of systemic effects. The lungs had no innervation, lymphatic drainage or bronchial circulation, which may affect perfluorocarbon elimination in vivo. They were not perfused to exclude possible effects of fluid filtration or perfluorocarbon loss via the perfusate. To prevent any loss of liquid via the pleural route the lungs were completely covered with a thin plastic foil which was impermeable to water and perfluorocarbon (liquid as well as vapour).

The instilled liquid volume $(\leqslant 15 \mathrm{~mL} \cdot \mathrm{kg}$ body weight ${ }^{-1}$ ) represents the functional residual capacity of rabbits. The perfluorocarbon compound (PF-5080) had a vapour pressure of $5.9 \mathrm{kPa}$ (44 Torr) at $25^{\circ} \mathrm{C}$. Because this pressure influences evaporation, different results with other perfluorocarbon compounds are expected (with higher or lower vapour pressures). However, qualitative effects of intrapulmonary liquid volume and respiratory settings on evaporative loss should be similar for different perfluorocarbon compounds. In addition, vapour pressure of a specific perfluorocarbon compound increases with increasing temperature. This study was performed at room temperature, higher elimination rates are likely at higher temperatures.

The current authors determined perfluorocarbon loss gravimetrically. In control experiments the fact that lung weight decreased in a relevant fashion during gas ventilation (e.g. due to expired water vapour) or decreased following perfluorocarbon instillation without subsequent ventilation (due to ventilation-independent loss of perfluorocarbon) was excluded. Because lungs take up oxygen for their own metabolism from the alveolar air [17] and have stored enough substrate for several hours without perfusion [18] the absence of perfusion should not have affected the results. The lungs were ventilated with $5 \% \mathrm{CO}_{2}$ in air to avoid hypocapnia, which may have resulted in adverse pulmonary effects, i.e. increased airway permeability or dysfunctional surfactant [19-21].

For extrapolation of the results to the in vivo setting various methodical aspects have to be considered. First, the effects of PEEP on the distribution of lung volumes as well as of perfluorocarbons within the airways may differ between isolated lungs and the closed-chest situation. In anaesthetised patients, it has previously been observed that under open-chest conditions dynamic lung elastance increased and responded differently to changes in end-expiratory pressure when compared to closed-chest conditions while effects on airway resistance remained comparable [22]. In dogs, differences between the mechanical properties of the airways and the lung tissues were observed in situ and in open-chest conditions [23]. Thus, the application of PEEP may have more pronounced effects on airways and tissue properties in isolated lungs (and under open-chest conditions) than under closed-chest conditions. It is unclear to what extent these differences play a role for perfluorocarbon evaporation.

Secondly, intrapulmonary perfluorocarbon distribution and elimination may vary with changes in posture. In neonatal lambs it was observed that evaporation (assessed as per cent of perfluorocarbon saturation in the expired air) increased by $20 \%$ when animals were turned from supine to prone [24]. Thus, the same intrapulmonary liquid volume may be associated with different evaporation values after intrapulmonary liquid redistribution. Therefore, for the study of the effects of intrapulmonary liquid volume and respiratory settings on perfluorocarbon evaporation a fixed lung posture would be desirable. In the present study, the lungs were suspended from a force transducer and their position was kept constant throughout the experiments.

Thirdly, the isolated lungs were studied at atmospheric pressures and they were allowed to collapse before the experiments started. The absence of subatmospheric pressures, such as in the pleural cavity, may have reduced initial lung gas volume below functional residual capacity. This may have also reduced the ratio between the relative gas volume and the intrapulmonary liquid volume. It is 
unclear to what extent this ratio affects ventilation/ perfluorocarbon fluid contact area and thus evaporative loss.

Finally, in addition to the effects of the chest wall and posture, lung abnormalities (for instance during acute respiratory distress syndrome) may influence the effects of positive end-expiratory pressure on regional distribution of ventilation [25-27]. Using computed tomography (CT) PUYBasset et al. [25] observed marked differences between patients with lobar and diffuse CT attenuations. While PEEP preferentially distended compliant upper lobes without recruiting atelectatic regions with lobar attenuations, PEEP is more evenly distributed within the lungs with diffuse CT attenuations allowing homogenous alveolar recruitment of poorly compliant upper and lower lobes. Because perfluorocarbons primarily flow to dependent lung regions, it is possible that the effects of PEEP on evaporation are also influenced by the type of lung abnormality.

Effects of liquid volume, tidal volume, respiratory rate and positive end-expiratory pressure on perfluorocarbon evaporation

At constant respiratory settings, intrapulmonary liquid filling had a nonlinear effect on evaporative loss from the isolated lungs. Mean evaporation was $13 \%$ lower with an intrapulmonary liquid volume of $5 \mathrm{~mL} \cdot \mathrm{kg}^{-1}$, rather than with a volume of $15 \mathrm{~mL} \cdot \mathrm{kg}^{-1}$, representing a value near the functional residual capacity of New Zealand white rabbits. These results are consistent with previous in-vivo studies measuring perfluorocarbon concentrations in the expired air in which the perfluorocarbon concentration was found to decrease over time and with smaller initial doses [1-6].

When intrapulmonary liquid volume was kept constant evaporative loss was proportional to respiratory rate and tidal volume, which were varied over a wide range (respiratory rate: factor 4; tidal volume: factor 3). At constant minute ventilation there was a tendency for a decrease in perfluorocarbon elimination with higher respiratory rates. This is possibly explained with a higher dead-space ventilation. In previous in vivo observations evaporative loss also depended on minute ventilation, however, alterations in respiratory rate had little effects on perfluorocarbon loss profile, as long as minute ventilation was maintained constant [6].

It was hypothesised that increases in end-expiratory pressure would also increase end-expiratory volume and thus the air/liquid interface from which perfluorocarbons evaporate in the expired gas during partial liquid ventilation. Indeed, in in-vivo observations [28], as well as in pilot experiments in dogs in the current authors' laboratory, evaporation increased when end-expiratory pressure was increased, and decreased when end-expiratory pressure was decreased. In isolated lungs, however, it was observed that evaporation was reduced when end-expiratory pressure was increased from zero to a value of $10 \mathrm{cmH}_{2} \mathrm{O}$. It is speculated that these differences are explained by different effects of PEEP on intrapulmonary distribution of perfluorocarbons within isolated and normal lungs. It is possible that in isolated lungs increases in end-expiratory pressure redistributes more perfluorocarbon to dependent lung regions and more ventilation to nondependent regions (which contain less liquid) than during the closed chest condition. These effects could result in less evaporation from isolated lungs with increasing levels of end-expiratory pressure.

To conclude, the experiments suggest that evaporative loss of perfluorocarbons during partial liquid ventilation of isolated lungs is increased with increasing intrapulmonary liquid volume, respiratory rate and tidal volume and is reduced in a level-dependent manner by the application of positive end-expiratory pressure.

\section{References}

1. Shaffer TH, Foust R 3rd, Wolfson MR, Miller TF Jr. Analysis of perfluorochemical elimination from the respiratory system. J Appl Physiol 1997; 83: 10331040.

2. Wolfson MR, Kechner NE, Roache RF, et al. Perfluorochemical rescue after surfactant treatment: effect of perflubron dose and ventilatory frequency. J Appl Physiol 1998; 84: 624-640.

3. Miller TF, Milestone B, Stern R, Shaffer TH, Wolfson MR. Effect of single versus multiple dosing on perfluorochemical distribution and elimination during partial liquid ventilation. Pediatr Pulmonol 1999; 27: 410-418.

4. Weis CM, Fox WW, Philips CM, Wolfson MR, Shaffer TH. Perfluorochemical elimination from the lungs: effect of initial dose. Pediatr Pulmonol 2000; 30: 324-329.

5. Miller TF, Milestone B, Stern R, Shaffer TH, Wolfson MR. Effects of perfluorochemical distribution and elimination dynamics on cardiopulmonary function. J Appl Physiol 2001; 90: 839-849.

6. Jeng MJ, Trevisanuto D, Weis CM, et al. Role of ventilation strategy on perfluorochemical evaporation from the lungs. J Appl Physiol 2001; 90: 1365-1372.

7. Reickert C, Pranikoff T, Overbeck M, et al. The pulmonary and systemic distribution and elimination of perflubron from adult patients treated with partial liquid ventilation. Chest 2001; 119: 515-522.

8. Meaney JFM, Kazerooni EA, Garver KA, Hirschl RB. Acute respiratory distress syndrome: CT findings during partial liquid ventilation. Radiology 1997; 202: 570-573.

9. Calderwood HW, Ruiz BC, Tham MK, Modell JH, Saga SA, Hood CI. Residual levels and biochemical changes after ventilation with perfluorinated liquid. J Appl Physiol 1975; 39: 603-607.

10. Kaisers U, Kuhlen R, Keske U, et al. Superimposing positive end-expiratory pressure during partial liquid ventilation in experimental lung injury. Eur Respir $J$ 1998; 11: 1035-1042.

11. Kirmse M, Fujino Y, Hess D, Kacmarek RM. Positive end-expiratory pressure improves gas exchange and pulmonary mechanics during partial liquid ventilation. Am J Respir Crit Care Med 1998; 158: $1550-1556$. 
12. Fujino Y, Kirmse M, Hess D, Kacmarek RM. The effect of mode, inspiratory time, and positive endexpiratory pressure on partial liquid ventilation. $\mathrm{Am}$ J Respir Crit Care Med 1999; 159: 1087-1095.

13. Zobel G, Rodl S, Urlesberger B, et al. The effect of positive end-expiratory pressure during partial liquid ventilation in acute lung injury in piglets. Crit Care Med 1999; 27: 1934-1939.

14. Manaligod JM, Bendel-Stenzel EM, Meyers PA, Bing DR, Connett JE, Mammel MC. Variations in end-expiratory pressure during partial liquid ventilation: impact on gas exchange, lung compliance, and end-expiratory lung volume. Chest 2000; 117: 184-190.

15. Uchida T, Yokoyama K, Nakazawa K, Makita K. Partial pressure of oxygen and partial pressure of carbon dioxide of perfluorocarbon liquid during partial liquid ventilation: their regional difference and their dependence on tidal volume and positive end-expiratory pressure level. Intensive Care Med 2001; 27: 36-41.

16. Max M, Kuhlen R, Falter F, Reyle-Hahn M, Dembinski R, Rossaint R. Effect of PEEP and inhaled nitric oxide on pulmonary gas exchange during gaseous and partial liquid ventilation with small volumes of perfluorocarbon. Acta Anaesthesiol Scand 2000; 44: 383-390.

17. Loer SA, Scheeren TWL, Tarnow J. How much oxygen does the human lung consume? Anesthesiology 1997; 86: 532-537.

18. Bishop MJ, Holman RG, Giudotti SM, Alberts MK, Chi EY. Pulmonary artery occlusion and lung collapse depletes rabbit lung adeonsine triphosphate. Anesthesiology 1994; 80: 611-617.

19. Reynolds AM, Zadow SP, Scicchitano R, McEvoy RD. Airway hypocapnia increases microvascular leakage in the guinea pig trachea. Am Rev Respir Dis 1992; 145: 80-84.

20. Cutillo A, Omboni E, Perondi R, Tana F. Effect of hypocapnia on pulmonary mechanics in normal subjects and in patients with chronic obstructive lung disease. Am Rev Respir Dis 1974; 110: 25-33.

21. Laffey JG, Engelberts D, Kavanagh BP. Injurious effects of hypocapnic alkalosis in the isolated lung. Am J Respir Crit Care Med 2000; 162: 399-405.

22. Dechman GS, Chartrand DA, Ruiz-Neto PP, Bates $\mathrm{JH}$. The effect of changing end-expiratory pressure on respiratory system mechanics in open- and closedchest anesthetized, paralyzed patients. Anesth Analg 1995; 81: 279-286.

23. Suki B, Petak F, Adamicza A, Hantos Z, Lutchen KR. Partitioning of airway and lung tissue properties: comparison of in situ and open-chest conditions. J Appl Physiol 1995; 79: 861-869.

24. Shaffer TH, Foust R III, Wolfson MR, Miller TF. Analysis of perfluorochemical elimination from the respiratory system. J Appl Physiol 1997; 83: 10331040.

25. Puybasset L, Cluzel P, Gusman P, Grenier P, Preteux $\mathrm{F}$, Rouby JJ. Regional distribution of gas and tissue in acute respiratory distress syndrome. I. Consequences for lung morphology. CT Scan ARDS Study Group. Intensive Care Med 2000; 26: 857-869.

26. Gattinoni L, Pelosi P, Crotti S, Valenza F. Effects of positive end-expiratory pressure on regional distribution of tidal volume and recruitment in adult respiratory distress syndrome. Am J Respir Crit Care Med 1995; 151: 1807-1814.

27. Dueck R, Wagner PD, West JB. Effects of positive end-expiratory pressure on gas exchange in dogs with normal and edematous lungs. Anesthesiology 1977; 47: 359-366.

28. Trevisanuto D, Jeng MJ, Weis CM, Fox WW, Wolfson MR, Shaffer TH. Positive end-expiratory pressure (PEEP) modulates perfluorochemical (PFC) evaporation from the lungs. Pediatr Res 2000; 47: 2581. 